\title{
Quando as políticas curriculares e a pesquisa educacional mandam: reflexões sobre a colonização do trabalho docente ${ }^{1}$
}

\author{
Sandra Escovedo Selles \\ Faculdade de Educação \\ Universidade Federal Fluminense \\ Associação Brasileira de Pesquisa em Educação em Ciências - ABRAPEC \\ escovedoselles@gmail.com
}

\section{Resumo}

Este artigo se propõe a examinar o tratamento reservado às práticas docentes pelas políticas curriculares e pela pesquisa educacional, especialmente a da área de Educação em Ciências e Matemática. São apresentadas contribuições de autores que discutem a autonomia docente, como referências para analisar textos de políticas curriculares e de pesquisa que parecem mais despotencializar a docência e seus sujeitos do que reafirmá-los profissionalmente. Por um lado, argumenta-se que políticas curriculares que associam currículo único a um sistema de avaliação de larga escala submetem a ação docente ao controle por meio de gerenciamentos, meritocracia, ranqueamentos, sistemas de bonificação e uso de materiais pedagógicos de caráter genérico e homogêneo. Por outro lado, sugere-se que pesquisas pautadas por normatividade também assumem voz de mando, quando pretendem afirmar o que o professor deve saber, fazer e ser. Por fim, o artigo provoca uma reflexão acerca da agenda de pesquisa educacional de modo a fortalecer a profissão docente.

Palavras-chave: Políticas curriculares. Pesquisa em Educação em Ciências e Matemática. Formação docente. Autonomia docente.

\section{When curriculum policies and educational research order: reflections about teaching colonization}

\begin{abstract}
This article aims to examine curriculum policies and educational research - specially the science education and mathematics ones - when they focus on teaching practices. Theoretical contributions regarding teaching autonomy are used in the article to analyse both curriculum policies documents and research production in this area. This analysis suggests that a number of them diminish teaching instead of reassure it in professional basis. On one hand the article argues that curriculum policies, which attach curriculum to large-scale exams, control teachers practices through the use of managements, meritocracy, ranking, prizes and the use of curriculum materials homogenously designed. On the other hand, the article suggests that educational research guided by normativity
\end{abstract}

\footnotetext{
${ }^{1}$ Este artigo é fruto da aula inaugural da autora no Programa de Pós-Graduação em Educação em Ciências e Matemática do Instituto de Educação da UFRRJ, em 17 de abril de 2015.
} 
also controls and says to teachers what to know, do and be. Finally, the article intends to propose a reflection about educational agenda as a means to strength teaching profession.

Keywords: Curriculum policies. Research in Science and Mathematics Education. Teacher education. Teacher autonomy.

\section{Introdução}

No Brasil, dentre um quantitativo que reúne mais de 2 milhões de professores, 52.722 professores ${ }^{2}$ de Biologia ${ }^{3}$ exercem sua atividade profissional em um contexto socioeducacional que lhes coloca desafios de diversas ordens. Sobretudo, estes docentes veem-se provocados não apenas pelo número expressivo de alunos que frequentam as escolas públicas de Ensino Médio - na magnitude de 7 milhões -, mas também pela diversidade dos jovens que frequentam suas salas de aula: são muitos e diferentes jovens ${ }^{4}$. Como traço que certamente aproxima o cotidiano educacional escolar brasileiro ao de muitos na América Latina, esses jovens carregam para as aulas suas angústias e seu lugar de insegurança em espaços sociais que lhes ameaçam com futuro incerto em um cotidiano eivado de questões de sobrevivência, falta de segurança e desestabilidades. Autores, como Cury (1991), afirmam que o Ensino Médio, em sua condição de terminalidade da Educação Básica brasileira, explicita "o nó da relação social" na educação nacional, isto porque as relações com o saber em uma sociedade desigual encontram-se tensionadas no currículo, entre formar para o uso do conhecimento ou valorizá-lo em si mesmo.

Deste modo, cabe indagar o sentido de ensinar - e de aprender - Biologia, quando muitos desses jovens "estão administrativamente inscritos na escola, frequentam-na do ponto de vista físico, mas nunca verdadeiramente nela entraram” (NÓVOA, 2011, p. 538). Em outras palavras, a utilidade do Ensino Médio e de seus saberes se mostra abstrata para muitos dos estudantes. Daí esse mesmo autor afirmar que o maior desafio colocado à docência é ensinar a quem não deseja, não vê interesse em aprender. Esse desafio está posto para os professores das diversas disciplinas e assume centralidade nas reflexões que sustentam este artigo: como pensar o ensino das disciplinas escolares para jovens que saturam as aulas com seu desinteresse, ou melhor, que se interessam por atividades outras - numa contemporaneidade plena de atrativos que competem com os saberes escolares -,

\footnotetext{
${ }^{2}$ Disponível em http://www.observatoriodopne.org.br/metas-pne/15-formacao-professores/indicadores. Acesso em $21 / 12 / 2015$

${ }^{3}$ Neste artigo, faço diversas alusões à disciplina escolar Biologia e Ciências, ou mesmo à formação dos docentes nestas áreas, por se tratar de uma das referências de onde construo minhas reflexões ao longo de minha trajetória acadêmica. Entretanto, a discussão que proponho ao longo do artigo não se circunscreve a esta disciplina.

${ }^{4}$ Sinopse Estatística da Educação Básica - 2014 (Instituto Nacional Estudos e Pesquisas Educacionais Anísio Teixeira) http://portal.inep.gov.br/basica-censo-escolar-sinopse-sinopse, acesso em 17/08/2015.
} 
confrontando-os com as seleções curriculares e os métodos de ensino empregados nas aulas dessas disciplinas?

Diante das variadas funções que a escola pública brasileira assume, afirma Dalila Oliveira (2004, p.1132) que "os docentes têm de responder a exigências que estão além de sua formação", demandando deles "desempenhar funções de agente público, assistente social, enfermeiro, psicólogo, entre outras" que "contribuem para um sentimento de desprofissionalização, de perda de identidade profissional, da constatação de que ensinar às vezes não é o mais importante" (grifo nosso). Ensinar Biologia a jovens com perfis de desinteresse, com necessidades distintas e imersos em conflitos sociais, expõe a fragilidade dos docentes em lidar com dimensões educacionais que tanto mostram o deslocamento de seu objeto profissional quanto obscurecem as possibilidades pedagógicas de exercê-las, de modo a promover um encontro com o conhecimento escolar biológico. Visto deste modo, as preocupações didáticas e o zelo pelas características tão defendidas na literatura da área de Educação em Ciências e Matemática parecem diluir-se no cotidiano da sala de aula.

Entretanto, e a despeito de todo o pessimismo que este quadro parece anunciar, as escolas e as aulas de Biologia, como as das demais disciplinas, permanecem como oficinas de práticas que mais as afirmam como o reduto da esperança e do labor do que o lugar da inoperância. Isso não é trivial e cabe indagar o que continua provocando nos professores, nas mais diferenciadas fases do exercício profissional, e em condições desfavoráveis, o desejo de perseguir o desafio a que se refere António Nóvoa de organizar suas aulas tendo como horizonte alunos que não veem interesse na escola.

Há de se considerar que há na docência uma dimensão moral (e não moralizante) e ética que movimenta os professores a perseguir finalidades mesmo quando a adversidade parece negar o sentido de sua profissão. Há de se pensar que os professores constroem suas práticas - e as disciplinas escolares com as quais organizam seu trabalho e são por ele organizadas -, tomando como referência seu crescimento pessoal e profissional, conforme assinala IvorGoodson (1997, p. 27): “A disciplina escolar é construída social e politicamente e os atores envolvidos empregam uma gama de recursos ideológicos e materiais para levarem a cabo as suas missões individuais e coletivas." Isto permite reconhecer que existe um sentido nesta construção disciplinar que é reafirmado pelo docente e que resiste a acusações de negligência, despreparo, incapacidade, inoperância, as quais circulam midiaticamente e, talvez mais lamentavelmente, no próprio contexto educacional.

É contra essas acusações que deixam acuados os professores diante de tantas exigências saber profundamente os conteúdos, mobilizar com maestria técnicas e metodologias inspiradas nas 
Ciências Biológicas, afirmar a natureza da Ciência alinhada com as contribuições mais atualizadas da História e Filosofia da Ciência, estar atento às relações entre Ciência, Tecnologia e Sociedade, adotar a interdisciplinaridade como princípio pedagógico e metodológico, introduzir as questões culturais etc. - que este texto se propõe a enfrentar. Muitas dessas exigências, ainda que legítimas, guardam a relação de exterioridade com os saberes docentes, conforme se refere Maurice Tardif (2002). Talvez seja também o caso de afirmar que os professores são muitos e diversos.

Diante de tarefas exercidas "against the grain"5 e do constrangimento imposto aos docentes que sempre são cobrados pelo que não fazem, nem são reconhecidos pelas invenções que criam no seu cotidiano, cabe a pergunta: quem decide sobre o sistema escolar e quais são os interesses que movem as intervenções sobre o currículo, o trabalho docente e as relações de poder da escola? Qual o espaço reservado ao professor nessas decisões? Estas indagações remetem a territórios curriculares que mostram o lugar sitiado no qual se encontram os docentes, pois não somente no domínio das políticas as decisões são tomadas, reforçando o lugar de subalternidade ${ }^{6}$, mas também em espaços acadêmicos são produzidas reivindicações ao trabalho docente nem sempre pautadas pelo reconhecimento do caráter produtivo de suas ações. Mais especificamente, desejo discutir neste artigo como (e se) a pesquisa educacional pode informar as políticas curriculares e a prática docente na área de Educação em Ciências e Matemática.

Argumento neste artigo que existe o risco - e no limite, a advertência - de que as pesquisas e as políticas curriculares subalternizam a escola e os professores, subvertendo a autonomia (ainda que relativa) da prática docente e da construção curricular. Construo meu texto, apresentando contribuições de autores que discutem a autonomia docente, para em seguida analisar textos de políticas curriculares e de pesquisa que parecem mais despotencializar a docência e seus sujeitos do que reafirmá-los profissionalmente.

\section{A profissão docente escrutinada}

A ideia que sustenta este texto, e que me produz tanta inquietação, diz respeito ao tratamento reservado às práticas docentes pelas políticas educacionais, dentre as quais se destacam as políticas curriculares, e pela pesquisa educacional. Talvez se pudesse dizer, sem exagero, que nunca a alma do professor foi tão disputada, ainda que o processo de subordinação dos docentes a decisões que lhes fogem do controle seja um longo e histórico processo.

\footnotetext{
${ }^{5}$ Expressão da língua inglesa que pode ser traduzida para o português como, "estar na contramão" ou "remar contra a maré". Utilizo a expressão inglesa porque é empregada por pesquisadores anglo-saxões que investigam práticas de docentes que, a despeito de adversidades de ordem política ou pedagógica, realizam práticas comprometidas eticamente com a docência e com o desenvolvimento escolar de seus alunos. Ver, por exemplo, Cochran-Smith (1991) e Carlone; Frank; Kimmet (2010).

${ }^{6}$ A este respeito ver Selles e Andrade, 2016.
} 
Recuando aos anos 1950, quando no Brasil figuravam intensas proposições de melhoria da educação científica, conhecidas como "Movimento de Renovação do Ensino de Ciências", não eram incomuns afirmações de que eram os cientistas os mais capacitados a decidir sobre o que e como ensinar Ciências. Em trabalho anterior (SELLES; FERREIRA, 2008) examinamos onze relatórios parciais da Subcomissão Ciência do IBECC/SP ${ }^{7}$, escritos entre 1962/63, na sua maior parte por Isaías Raw, diretor científico da instituição, além de documentos curriculares ${ }^{8} \mathrm{e}$ depoimentos produzidos por lideranças do movimento renovador. Registramos a compreensão por parte do IBECC/SP de que as ações curriculares defendidas por este movimento teriam que ser lideradas por "cientistas ativos", os únicos legitimamente capazes de "estabelecer o quê e o como ensinar", como o excerto que segue:

O pressuposto inicial de nosso projeto considera que a função do cientista é avaliar o impacto da Ciência para a educação em geral e para a vida cotidiana. É o cientista que deve rever continuamente a evolução da Ciência e relacioná-la às mudanças de nosso país, direcionando o ensino de Ciências. No presente estágio da vida humana não se pode depender das autoridades burocráticas ou dos especialistas em educação geral para decidir sobre o currículo de ciências na escola e sobre quais aspectos da Ciência são ou não importantes e fundamentais (SELLES; FERREIRA, 2008, p. 6, grifo nosso) ${ }^{9}$.

Examinando documentos deste período, Maria José Almeida (2009) refere-se a "recomendações prescritivas" que pretendem "dizer ao professor o quê, quando e como trabalhar com seus alunos", as quais tendem a reduzir o professor a ser

[...] o animador de um auditório no qual ele expõe conhecimentos prescritos pelos que se consideram e são considerados especialistas no ato de ensinar. Eles encarregam-se de estabelecer a matéria que o professor deve passar aos alunos e também determinam como ele deve fazê-lo. (ALMEIDA, 2009, p. 98)

Inúmeros professores das Ciências e de Biologia, por exemplo, passaram a ter à sua disposição, e de modo crescente no Brasil dos anos 1970 em diante, cursos com prescrições de

\footnotetext{
${ }^{7}$ O Instituto Brasileiro de Educação, Ciência e Cultura (IBECC) foi fundado em 1946 como uma comissão nacional da UNESCO no Brasil (Decreto Federal no. 9335 de 13 de janeiro de 1946. Fonte: DO NO. 135). A Subcomissão Ciência recebeu, nos anos de 1950/60, apoio financeiro de agências como Fundação Ford, Fundação Rockfeller e União Panamericana (MARANDINO; SELLES; FERREIRA, 2009). A Subcomissão Ciência sediada na Universidade de São Paulo centralizou as ações inovadoras no país, sob a direção de Isaías Raw, um reconhecido cientista da Faculdade de Medicina daquela instituição. Sua ênfase recaiu sobre a produção de materiais didáticos e de equipamentos laboratoriais que tornassem o ensino de Ciências experimental e, nesse contexto, a produção de livros didáticos foi uma das prioridades do IBECC/SP (SELLES; FERREIRA, 2008, p. 3).

${ }^{8}$ Estes relatórios encontram-se no Arquivo Nacional dos Estados Unidos no âmbito da documentação do Departamento de Estado Americano, no período de 1958/70. Além de Isaías Raw, também assinam dois documentos Rachel Gevertz que escreve em parceria com ele -, Myriam Krasilchik, que escreve o relatório relativo aos institutos de verão em Biologia, e Enerst Giesbrecht, que escreve o relatório sobre o CBA no Brasil. A documentação brasileira foi perdida em um incêndio ocorrido na sede do IBECC/SP, no início dos anos 2000.(SELLES, 2007. Relatório Final do Projeto de Pós-Doutorado).

${ }^{9}$ RAW, I. Partial report, No. 1, Oct. 1962, p. 1.
} 
como ensinar melhor a fisiologia vegetal, como produzir modelos de células, como fazer com que os alunos aprendessem o Ciclo de Krebs ou o rendimento energético com maior produção de moléculas de ATP, apenas para dar alguns exemplos. O que se torna crítico é que muitas dessas iniciativas mostravam cientistas que atribuíam a si o domínio irretocável do conteúdo e sua articulação a métodos de ensino inspirados no trabalho científico, disputando com educadores em geral e especialistas em ensino (e por que, não, pesquisadores em Educação em Ciências) a prerrogativa de decidir o que era melhor para os professores, tendo em vista a necessidade dos alunos, quando ensinar e como ensinar Biologia. Algo próximo do modo com que Dominique Colinvaux (2008) retrata a disputa territorializada pelo currículo de ciências nos anos 1950-70 entre os profissionais que nele trabalhavam,

Ainda que de modo simplista, estes projetos [elaborados no âmbito da reforma curricular científica dos Estados Unidos nos anos 1950-60] podem ser resumidos como segue: aos cientistas, cabia indicar o que ensinar; os psicólogos determinavam quando ensinar e, finalmente, os educadores eram responsáveis por elaborar como ensinar. (COLINVAUX, 2008, p.3)

Mais de meio século depois, encontramos defesas semelhantes às que se referiam os registros brasileiros do movimento de renovação do ensino de Ciências mencionados anteriormente. Nesta disputa, produziu-se na literatura educacional, de modo geral, e na literatura em Educação em Ciências, em particular, um verdadeiro prontuário de como formar professores, de modo que, por meio desta formação, se melhorasse o ensino. De modo análogo, mudanças sobre as práticas docentes vêm sendo indicadas como se tratassem de receituário que permitiria sanar os males próprios de uma profissão não afirmada socialmente. Oscilando entre as justificativas sobre as necessidades dos alunos ou a dos próprios professores, temos assistido a modos diversos e sofisticados de tentar reformar a profissão docente informando o que os professores devem fazer, sem conhecer exatamente o que fazem, o que sabem para além de conhecimentos oriundos de sua formação.

O que haveria de errado - se aqui também coubesse um juízo de valor - em cursos, orientações e treinamentos que ensinassem os professores a melhor produzir suas aulas? Em que residiria a dimensão problemática dessas abordagens? Penso que a questão está na orientação normativa que parece dominar tais abordagens. Denomino esse processo, que aborda de modo hierarquizado as necessidades dos professores, de colonização do trabalho docente, expressando controle e regulação que pretendem produzir modelos de "bom professor", "boa aula", "bom ensino de biologia", "boa escola”, “ bom currículo" ...

Encontramos em António Nóvoa (2011) uma síntese que nos ajuda a identificar elementos desse processo de colonização do trabalho docente. O autor afirma que o "regresso dos professores" 
nos últimos 40 anos à cena educativa vem gerando como subproduto a invisibilidade social dos professores, com o deslocamento do interesse para outros problemas: planejamento do ensino, nos anos 1970; as reformas curriculares dos anos 1980; a gestão escolar, nos anos 1990; a questão das tecnologias digitais, na década passada etc. Da invisibilização ao silenciamento, três perspectivas de controle e regulação docente emergem: a dos investigadores e da pesquisa educacional; a dos especialistas que prestam consultoria aos centros internacionais formuladores de políticas para a educação; e mais recentemente - e de modo crescente - a da indústria do ensino, levando Nóvoa a ponderar o risco que reside em pautar "o ritmo educativo por uma lógica do mercado e de impor às escolas critérios de eficácia que não levam em conta a especificidade do trabalho pedagógico" (NÓVOA, 1995, p. 7-10).

Com Nóvoa, reflito que talvez seja a especificidade do trabalho pedagógico que diferentes atores, que não os docentes, parecem secundarizar. Cabe então dirigir a atenção para a relação entre as práticas dos professores de Ciências e Matemática e as políticas curriculares, bem como as pesquisas produzidas pela comunidade de educadores dessa área, para explorar as distinções entre $o$ que cabe à pesquisa e o que cabe à política e, certamente, o que cabe ao professor na lida cotidiana de seu trabalho pedagógico. Penso que é produtivo reconhecer que a prática investigativa é distinta da prática política sem negar que a pesquisa educacional é social, cultural e politicamente implicada. Entretanto, isso não pode significar uma licença acadêmica para intervenções não autorizadas ou autoritárias sobre a prática do outro. Em outras palavras, essas delimitações parecem necessárias e instigantes para se pensar sobre a relação das políticas curriculares e da pesquisa sobre o trabalho de milhares de professores que atuam nas escolas brasileiras. Nas próximas seções passo a elaborar algumas reflexões que pretendem enfrentar esse questionamento.

\section{Quando as políticas curriculares disputam a alma do professor ...}

Em artigo recente (SELLES; ANDRADE, 2016), argumentamos que a autonomia docente encontrase sob ameaça no processo de implementação do Currículo Mínimo no estado do Rio de Janeiro ${ }^{10}$, especialmente porque este se atrela a um sistema de avaliações bimensais impostas a escolas

\footnotetext{
${ }^{10}$ O Currículo Mínimo do Estado do Rio de Janeiro foi elaborado em dois momentos subsequentes: em 2011 para os anos finais do Ensino Fundamental e para o Ensino Médio Regular (Matemática, Língua Portuguesa/Literatura, História, Geografia, Filosofia e Sociologia); em 2012 foi feita uma revisão destas disciplinas e a apresentação de nova elaboração para as demais (Ciências/Biologia, Física, Química, Língua Estrangeira, Educação Física e Arte). Antecipando outra política que se insinua no cenário educacional, o currículo do Rio de Janeiro anuncia questões que vêm sendo levantadas com a produção em curso da Base Nacional Curricular Comum, ainda que esta esteja em processo de preparação. (Ver http://www.rj.gov.br/web/seeduc/exibeconteudo?article-id=374742 - Acesso em 21/12/2015).
} 
públicas do Ensino Médio, que estão sob a ingerência deste estado ${ }^{11}$. A análise do texto que apresenta o currículo mínimo ${ }^{12}$ aos professores indica a intenção controladora sobre o trabalho docente.

$\mathrm{Na}$ apresentação do documento, encontram-se expressões que dizem que a proposta valoriza o trabalho coletivo, afirmando que "o currículo deve ser uma construção coletiva de todos os envolvidos no processo educativo", ou ainda destacando o respeito pelas "preferências e formas de ensinar dos professores". Retoricamente, justifica-se o currículo mínimo como "um ponto de partida mínimo", baseando-se em princípios de "harmonia" em "uma rede de ensino múltipla e diversa", enfatizando que este mínimo "precisa ainda ser elaborado e preenchido em cada escola, por cada professor, com aquilo que lhe é específico, peculiar ou the for apropriado". Como antecipando a resposta a críticas de homogeneização ou padronização dos alunos, o texto ressalta que o fato de ser um currículo mínimo

não significa homogeneização cultural; ao contrário, por ser mínimo, possibilita ao professor fazer escolhas mais adequadas à diversidade cultural dos alunos e à realidade de cada escola, já que terá espaço em seu plano de ensino para inserir os temas que considerar necessários para aprofundá-lo ou ampliá-lo, considerando a particularização por região ou mesmo a individualização por turma. (SEEDUC-RJ, Apresentação, grifo nosso)

Ademais, há de se analisar o modelo de gestão do trabalho docente apresentado pela SEEDUC-RJ em seu planejamento estratégico ${ }^{13}$. Nesse portal, a equivalência com o modelo empresarial é autoexplicativa, como é possível constatar nas imagens a seguir (Figuras 1 e 2).

\footnotetext{
${ }^{11}$ Em 2008, a SEEDUC-RJ criou o Sistema de Avaliação da Educação do Estado do Rio de Janeiro (SAERJ), objetivando analisar e acompanhar o desempenho dos alunos da rede pública do Rio de Janeiro nas áreas de Língua Portuguesa e Matemática, nas turmas do $5^{\circ}$ e do $9^{\circ}$ anos do Ensino Fundamental, da 3a série do Ensino Médio, das fases equivalentes da Educação de Jovens e Adultos (EJA), do 4o ano do Ensino Normal e dos que estão concluindo o Programa Autonomia. Em 2011 a SEEDUC-RJ cria o SAERJINHO, um sistema de avaliação diagnóstica bimestral do processo de ensino e aprendizagem nas escolas da rede pública estadual do Rio de Janeiro, voltado às disciplinas de Língua Portuguesa, Matemática e Ciências para o $5^{\circ}$ e $9^{\circ}$ anos do ensino fundamental. Para as disciplinas de Biologia, Química e Física são aplicadas provas para todo o Ensino Médio, Ensino Médio Integrado e Curso Normal. Tais provas são organizadas de acordo com a Matriz de Referência do Saerjinho, contemplando as competências e habilidades previstas para o bimestre, além dos pré-requisitos necessários para os anos/séries avaliados. O Saerjinho é obrigatório como uma das notas de avaliação do bimestre em que é aplicado, mas o seu valor é definido pela escola e/ou professor. (AYRES et al., 2015).

${ }_{12}$ Disponível em: http://www.rj.gov.br/web/seeduc/exibeconteudo? article-id=759820 . Acesso em 21/12/2015.

${ }^{13} \mathrm{http}$ ://www.rj.gov.br/web/seeduc/exibeconteudo?article-id=1687124 . Acesso em 21/12/2015.
} 
Figura 1 - Cartilha de Acompanhamento de Resultados

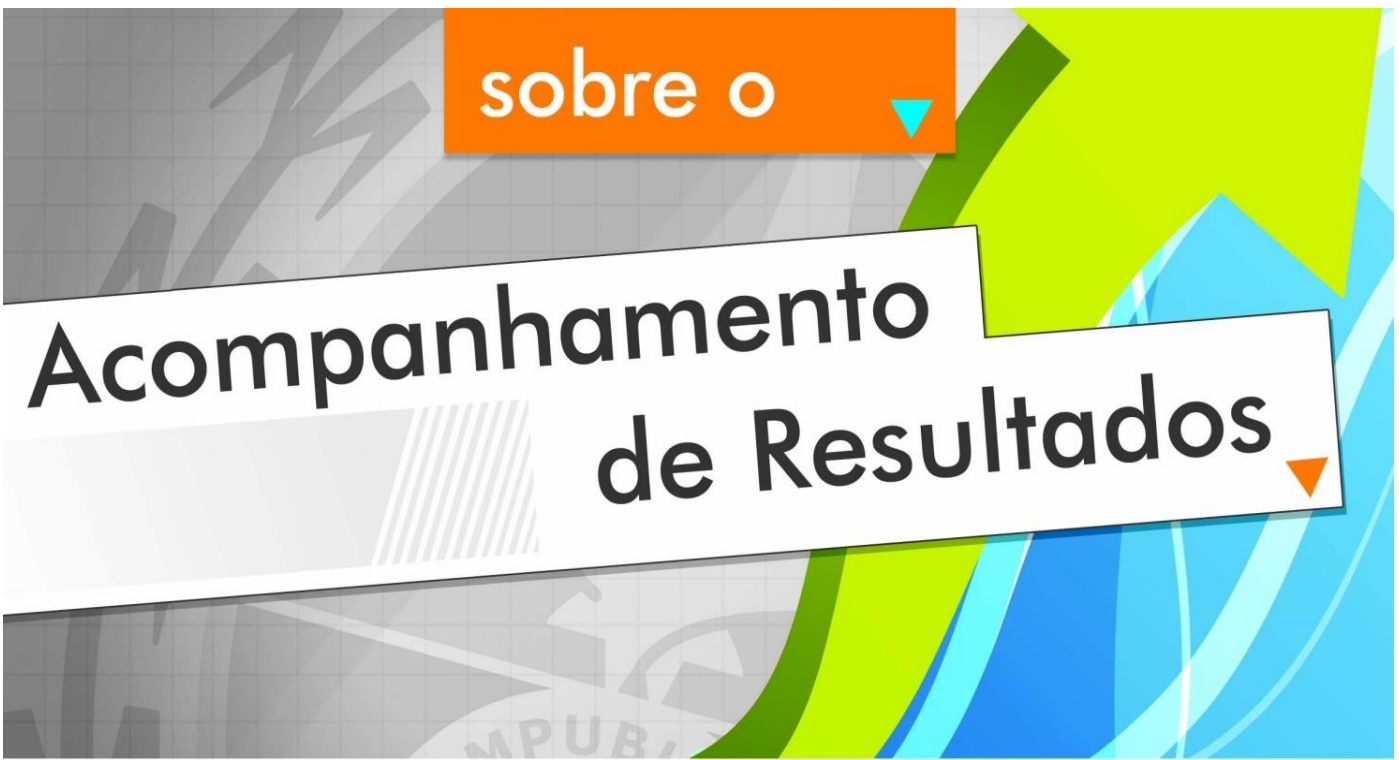

A partir do objetivo estratégico da Secretaria de Educacáa do Estado do Rio de Janeiro de estar entre os 5 melhores estados no ranking do IDEB de 2013, foram determinadas metas para as unidades escolares e Regionais para obter esse resultado.

Uma META é composta por:

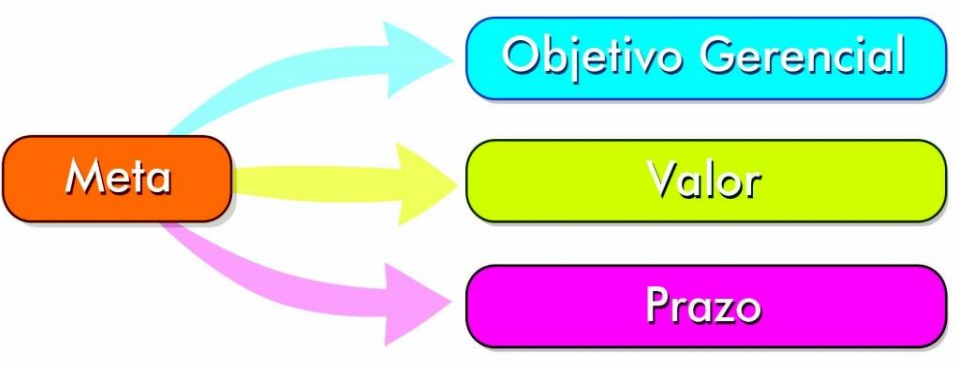

Quais indicadores estão sendo acompanhados?

O indicador principal dos resultados da SEEDUC é o IDEB, com periodicidade bianual. Para melhor acompanhar o processo ensino-apredizagem foi criado um indicador estadual - IDERJ com periodicidade anual e simulado ao longo dos bimestres.

Fonte: Parte do planejamento estratégico da SEEDUC. ${ }^{14}$

\footnotetext{
${ }^{14}$ Disponível em: http://www.rj.gov.br/web/seeduc/exibeconteudo?article-id=759820. Acesso em 21/12/2015.
} 
Figura 2 - Cartilha de Acompanhamento de Resultados

\section{3 de 4 ,o alcançar as metas?}

O caminho para alcançar as metas estabelecidas é o MÉTODO. Nas unidades escolares, nas Regionais e na SEEDUC foram elaborados Planos de Ação como ferramenta para se atingir os resultados desejados.

Caminho para a meta

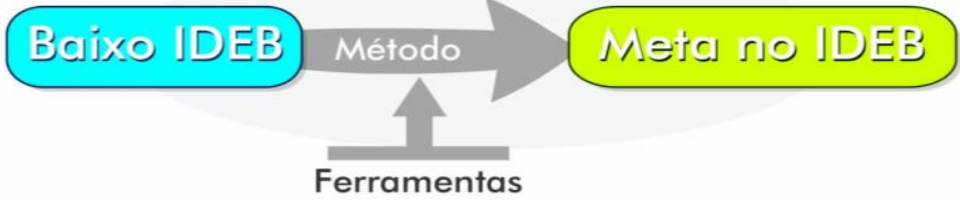

\section{A Sistemática de Acompanhamento de Resultados e Planos de Ação}

Por que definir metas?

As metas permitem o alinhamento dos esforços e a priorização de recursos das unidades escolares, das Regionais e dos Setores Suporte em consonância com os Objetivos Estratégicos da SEEDÚC.

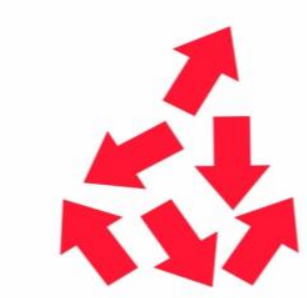

Projetos / Planos isolados

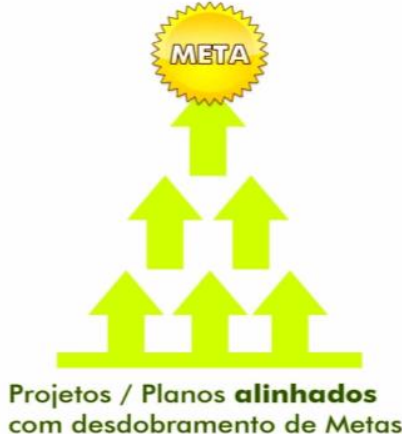

com desdobramento de Metas

Fonte: Parte do planejamento estratégico da SEEDUC.

Considero que há uma tentativa evidente de sequestrar o trabalho dos professores: o trabalho docente passa a ser controlado pelas exigências de eficiência que se tornam públicas por meio dos resultados do SAERJ - e seus impactos no IDERJ -, expondo as fragilidades de seus alunos. É por meio do desempenho destes que se avalia o quanto o professor foi eficiente nas aulas, nas explicações, nos recursos que utilizou, no seu esforço para cumprir o programa curricular e no desempenho dos alunos nos exames. $\mathrm{O}$ alinhamento dos projetos, planos de ação e dispêndio, em articulação com as metas traçadas, conferem à SEEDUC-RJ o controle estratégico sobre os resultados a serem alcançados pela rede de ensino. Processo semelhante é analisado por Michael Apple (1994) em relação aos contextos norte-americano e britânico, o que o leva a afirmar que os objetivos para a educação são os mesmos que orientam as metas para a economia. Neste sentido, currículo e avaliação estão intrinsecamente associados de modo a sitiar o professor no desempenho 
de suas funções pedagógicas para que correspondam a metas fixadas exteriormente, por sujeitos em situação de poder para avaliar e atribuir valores a essas funções ${ }^{15}$.

Poder-se-ia argumentar que a associação currículo/avaliação não foi inventada pela SEEDUC-RJ (ou por qualquer outra instância educativa de caráter normativo), pois não é raro encontrar registros de controle nas memórias docentes. Com efeito, Denice Catani e Paula Vincentini (2013), ao analisarem quatro autobiografias de professores, ainda que não pretendam discutir sobre a autonomia docente, reúnem evidências de tal controle em décadas anteriores a 1985, exercidas por inspetores de ensino ${ }^{16}$. Por exemplo, as autoras apresentam a narrativa de Botyra Camorim" ${ }^{17}$, a qual "dedicou boa parte de sua obra à denúncia da falta de apoio por parte de inspetores do ensino", caracterizados como "negligentes e muitas vezes grosseiros e intolerantes". Outra professora, Dora Lice ${ }^{18}$, quando na apresentação de sua autobiografia, dirige-se ao Secretário do Interior do Estado de São Paulo, fazendo referência aos inspetores, comparando-os "a feitores brutais" e "as professoras, a escravas" (CATANI; VINCENTI, p. 155). Abordando a questão do controle, Almeida (2009, p. 97) analisa discursos expressos em periódicos, atas de encontro de ensino, entrevistas e questionários de projetos e depoimentos de pesquisadores "em situações relacionadas com o ensino da física, no Brasil, em diferentes momentos desde a segunda metade do século passado" e reúne evidências de prescrições dirigidas a professores de Física da educação básica.

Tomando como base os registros dessas autoras, cabe ponderar que o controle sobre o trabalho docente não pode ser considerado inusitado, e certamente não caiba a comparação de "professoras com escravas" nem a existência de inspetores como "feitores". Ademais, há de se considerar também que uma dimensão do trabalho docente não é isenta de controle, posto que a docência apresenta uma faceta codificada, como se refere Maurice Tardif (2002). Cabe então perguntar o que diferenciaria a situação relatada por docentes, cuja atividade profissional se exerceu há mais de meio século, e a vivida pelos docentes do estado do Rio de Janeiro desde 2008. Entendo

\footnotetext{
${ }^{15}$ Refiro-me à gradação da bonificação que incide sobre as escolas como consequência do SAERJ e do SAERJINHO, implicando em valores pecuniários.

${ }^{16}$ O serviço de inspeção aos "estabelecimentos de ensino secundário" foi criado pelo decreto 19.890 de 18 de abril de 1931, que instituiu a inspeção permanente das escolas em cada distrito (capítulo I, artigos 51-56). Evidenciando o controle que orientava este decreto, os inspetores deveriam enviar mensalmente ao Departamento Nacional de Ensino, "em duas vias dactylographadas, um relatorio minucioso e de caracter confidencial, a respeito dos trabalhos de cada serie e cada disciplina da sua secção nos estabelecimentos do districto." (Art. 56). Este artigo assim enumerava a tarefa dos inspetores, exercidas "por meio de visitas frequentes": a) assistir a lições de exposições e demonstração pelo menos uma vez por mez; b) assistir igualmente, pelo menos uma vez por mez, a aulas de exercicios escolares ou de trabalhos praticos dos alumnos, cabendo-lhe designar quaes destes devam ser arguidos e apreciar o criterio de attribuição das notas; c) acompanhar a realização das provas parciaes, que só poderão ser effectuadas sob sua immediara fiscalização, cabendo-lhe ainda approvar ou modificar as questões a serem propostas;d) assistir ás provas finaes, sendo-lhe facultado arguir e attribuir nota ao examinado. (http://www2.camara.leg.br/legin/fed/decret/1930-1939/decreto-19890-18-abril1931-504631-publicacaooriginal-141245-pe.html - acesso em 21/12/2015)

${ }^{17}$ CAMORIN, Botyra. Uma vida no magistério. São Paulo: Saraiva, 1962.

${ }^{18}$ LICE, Dora. O calvário de uma professora. São Paulo: Gráficas Irmãos Ferraz, 1928.
} 
que, de modo crescente, o que passou a ocupar as preocupações dos docentes acerca do seu cotidiano profissional é a implementação agressiva dos modelos empresariais à escola. Tal ação coercitiva sobre o que fazem e sabem os professores é processo que vem sendo aprofundado desde os anos 1990, quando, em perspectivas neoliberais, currículo único e avaliação tornaram-se progressivamente um binômio inseparável, conforme afirmava Michael Apple em artigo publicado há mais de 20 anos:

O currículo nacional possibilita a criação de um procedimento que pode supostamente dar aos consumidores, escolas com 'selos de qualidade' para que as 'forças de livre mercado' possam operar em sua máxima abrangência. Se for para termos um mercado livre na educação, oferecendo ao consumidor um atraente leque de 'opções', então o currículo nacional e sobretudo o sistema de avaliação nacional atuarão, em essência, como uma 'comissão de vigilância do Estado' para controlar os 'excessos do mercado'. (APPLE, 1994, p. 74-75, grifo nosso)

Com efeito, a educação vista como mercadoria tem sido objeto de críticas em diversas publicações, sejam elas resultado de macroanálises com orientação marxista (OLIVEIRA, 2009; LIMA, 2005), sejam por estudos em outras perspectivas teóricas (CUNHA, 2007; HADDAD; GRACIANO, 2004), que expõem os interesses de grupos privatistas sobre a escola, os quais encontram nesta um nicho para auferir rendimentos. Esses interesses, ainda que insistam em afirmar que se colocam ao lado do professor para dar impulso a seu crescimento e ressaltem as bases meritocráticas como modo de promovê-lo, não podem ser confundidos com a defesa da autonomia docente que vem sendo historicamente defendida pela literatura pedagógica (CONTRERAS, 2002; MOREIRA, 2012). Entretanto, tais interesses estão muito mais próximos do que Elizabeth Macedo discute como "edu-business" (MACEDO, 2014, p. 1541), isto é, quando soluções sócioempresariais e de mercado são referência para os problemas educacionais. Em outras palavras, embora circule uma retórica que pretende afirmar um desejo altruísta com o futuro da sociedade brasileira (não apenas em nosso país, pois esses interesses têm um caráter globalizado), são os interesses econômicos de grupos e empresas que intervêm na instituição escolar ${ }^{19}$.

Esses grupos - e a ideologia que os sustentam - pretendem "consertar" as mazelas da escola servindo-se de operações métricas e estatísticas para localizar os problemas, fixar as metas e o tempo de execução destas, exercendo controle sobre as etapas de desenvolvimento das atividades escolares e de seus resultados. Por meio desta estratégia própria à "engenharia de produção", cuja mostra pode ser vista nas figuras 1 e 2 , as escolas e seus sujeitos se veem confundidos e rendidos por entre afirmações de sua falência. Submetidos a ingerências externas que negam sua autonomia profissional, os professores são retratados como incapazes e responsáveis pelo fracasso do presente

\footnotetext{
${ }^{19}$ No artigo publicado em 2014, Elizabeth Macedo escrutina algumas dessas redes privatistas que intervêm sobre a produção das Bases Curriculares Comuns Nacionais (BNCC) pela SEB/MEC. A análise produzida por Macedo tem ressonância sobre a do presente artigo.
} 
e do futuro de seus alunos. Reduzidos a problemas que precisam ser solucionados ou a enfermos que precisam de atendimento terapêutico, esses profissionais são submetidos a processos como os publicados pelo portal da SEEDUC-RJ, os quais exaltam a meritocracia.

A demanda obsessiva por eficiência oferece aos docentes as receitas de alcançá-la, anunciando que a escola "tem jeito", o que falta é consertar o método (Figura 2), ou seja, desde que os docentes sigam as orientações da SEEDUC-RJ, ou da consultoria externa que oferece seus serviços para este fim, como o fazem a demais empresas, e que são reproduzidos em reuniões pedagógicas ou em ofícios endereçados às escolas. Por meio da divulgação ampla de resultados expressos em números, o ranqueamento educacional "fabrica o professor eficiente", como nos adverte Popkewitz (2013, p. 28), o que exclui os que não se ajustam às políticas cerceadoras, pois, “[...] a abstração do professor eficiente, que leva o aluno a obter altos escores em testes não é algo concreto que possa ser tocado ou definido. É sim uma invenção à qual são atribuídas magnitudes que preenchem o que constitui essa abstração." Para o autor ao parecerem "técnicos, objetivos e calculáveis" os números incorporam "a ideia de dar a todos a mesma oportunidade e representação" (POPKEWITZ 2013, p. 23), simulando estratégias democráticas que se colocam a favor da educação dos alunos.

Posso concluir esta seção - sem esgotar os problemas que ela anuncia - reconhecendo nas políticas curriculares educacionais uma instância que se destaca na disputa pela alma do professor. Ao disputá-la, interpelam e negam sua autonomia - ainda que relativa - ou, como prefere Luciano Mendes de Faria Filho, a autoria docente. O pesquisador opera com a noção de autoria que converge com a presente discussão, pois a considera "como uma das importantes dimensões do reconhecimento dos nossos colegas da escola básica" e a aula como portadora de "dimensão autoral”. Ambas as acepções - autonomia e autoria docente - são marcadas pelo respeito à produção dos professores, algo que não pode ser capturado pela engenharia dos números e do controle na disputa por sua alma.

Como argumentarei na seção seguinte, essa disputa não parece ser prerrogativa das instâncias administrativa e normativa representadas pelas secretarias de educação, pois sugiro que a disputa também se trava no reduto do discurso educacional que se constrói por meio da pesquisa.

\section{Quando a pesquisa manda}

A partir das reflexões que teci na seção anterior, a disputa pela alma do professor aparece circunscrita a interesses políticos que dão espaço a grupos privatistas, os quais impõem um modelo de engenharia de controle sobre o trabalho docente. Minha intenção nesta seção é problematizar a 
questão de controle sobre o professor quando este é exercido pela instância acadêmica. Ou dizer que a pesquisa também disputa a alma do professor.

Para isso, trago alguns indícios recolhidos de textos de pesquisa publicados em anais e artigos de ensino de Biologia. Cabe dizer que não me proponho a realizar uma análise extensa e compreensiva acerca desses artigos: não trago registros numéricos, nem os submeti a categorias analíticas sistematicamente organizadas. Procedi a uma busca quase que aleatória a Anais dos IV e V ENEBIO e a publicações da Revista da SBEnBio, entre os anos de 2012 a $2014^{20}$. Portanto, as reflexões que trago ilustram mais do que documentam sistematicamente os problemas que enumero. Para esta busca, utilizei como palavras-chave os termos "formação de professores" e "pesquisa".

Deste exame, encontrei expressões que remetem a uma visão que retrata os professores pelo que não têm: o docente surge nos relatos de pesquisas marcado por ser um profissional que é reconhecido por "déficit". Daí, encontram-se registros de que aos professores sempre "falta": preparação (para as aulas, para escolher o livro didático); conhecer as particularidades de seus alunos; se apropriar dos referenciais teóricos (inclusive para saber escolher o livro didático a adotar em suas turmas); o conhecimento atualizado de conteúdos; a variedade do uso de métodos que façam nascer interesse nos alunos; etc. Estabelecer os critérios para o reconhecimento do "bom professor", ou mesmo enumerar os requisitos que o distingue de outros (maus professores), também aparece na literatura de pesquisa, não só nos artigos consultados, mas inclusive em livros que carregam esse título.

Para o "bom professor" esperam-se atributos como "calma", "saber bem a matéria", "compromisso", "firmeza", entre tantos. Alguns desses atributos, se são inquestionáveis como prerrogativa profissional, assumem uma conotação que reforça o déficit docente ou, no limite, a culpa por não portar os atributos que dele são esperados. Os professores ainda são caracterizados como confusos, incapazes de gerir sua turma, monótonos, razão do desinteresse dos alunos, tradicionais (sem que possamos precisar o que isso quer dizer).

Talvez um exercício produtivo seja buscar o uso dos verbos quando se apresentam resultados de pesquisas nas quais os professores e sua formação estão envolvidos. Com efeito, o verbo "dever" - com o sentido de "ter obrigação de", ou "ter por obrigação" - apareceu com tanta frequência que praticamente poder-se-ia dizer que a recomendação mais importante que a pesquisa tem a fazer é dizer aos professores o que devem fazer, saber, falar, ler, estudar, ser etc.

Essa normatividade assumida em algumas pesquisas parece se aproximar daquela que, exercida por instâncias oficiais, não apenas confecciona um professor inexistente, mas também investe sobre os professores que vivem a docência como profissão concebendo-a de modo

\footnotetext{
${ }^{20}$ Ver em www.sbenbio.org.br
} 
idealizado, pautando-a por padrões inalcançáveis. Assim, a proximidade dessas visões de professores, tanto pelos documentos curriculares oficiais quanto por relatos de pesquisa, acaba por exercer um efeito que pretende regular a performance docente e acentuar o caráter enfermo de sua prática. Assumindo o tom de mando, a pesquisa também pode se colocar ao lado do autoritarismo das políticas que critica.

\section{Considerações finais}

Comecei este texto indagando sobre como entender docentes que, a despeito de quadros e diagnósticos tão desfavoráveis, insistem cotidianamente em práticas que mais reafirmam a docência do que a desqualificam. Declarar que os docentes são muitos e diferentes também implica em reconhecer que de suas diferenças podem nascer possibilidades inventivas sobre o trabalho que desenvolvem com os alunos, ou mesmo que qualquer tentativa de homogeneizá-los não apenas é ineficaz como impossível.

Pela discussão tecida ao longo do texto, trago elementos que fundamentam a ideia de que o controle das instâncias oficiais dirigido aos professores sustenta-se em medidas, retoricamente acompanhadas de expressões como "democracia", "melhoria", "escolha", "liberdade", ou mesmo "necessidade de sistematização curricular" que ofereçam chances iguais a todos os alunos, mas agem sobre o trabalho docente reduzindo as possibilidades de exercer a docência de forma autônoma ou autoral. Em outras palavras, são políticas curriculares, muitas delas carregando a autonomia dos professores como retórica, mas que submetem a ação docente à avaliação por meio de: gerenciamentos; meritocracia; ranqueamentos; sistemas de bonificação; uso de materiais pedagógicos de caráter genérico e homogêneo. Neste sentido, corre-se o risco de tratar (acriticamente) as políticas curriculares - e em especial, o currículo único, ou mínimo - como práticas terapêuticas, entendendo-as de modo progressivo, como se implicassem em melhoria da escola e de seu ensino.

Localizadas nos territórios da normatividade, as políticas educacionais elaboradas a partir de referências empresariais vêm recebendo críticas que tendem a argumentar o quanto ameaçam o potencial inventivo da docência. Essas políticas pretendem criar identidades docentes e discentes modeladas ideologicamente em referências mercadológicas, as quais alimentam o conceito de qualidade educacional em patamares idealizados. Em suma, como se fosse possível formulá-la sob a forma de um índice a ser calculado matematicamente.

Se é procedente afirmar que o discurso pedagógico produza críticas significativas a políticas curriculares que subalternizam os docentes, talvez o mesmo não possa ser dito quando se tratam das conclusões das pesquisas que focalizam as práticas dos professores. $\mathrm{O}$ discurso 
pedagógico também manda e tende a subalternizar a prática docente. Ainda que as referências trazidas neste texto se constituam uma análise exploratória, recolhidas de um quantitativo reduzido de evidências, elas são aqui mobilizadas para provocar uma reflexão que aprofunde, pelo menos, duas questões: Como as pesquisas em Ensino de Ciências e Biologia - como de resto todas desta área - dialogam com a escola, sem compreendê-la de modo utilitarista? Como abordamos a escola comprometidos em promover um diálogo de saberes e práticas? Penso que estas questões convergem para a advertência de dois autores que têm se dedicado ao estudo da formação e prática docente, por de "dentro".

Por um lado, Maurice Tardif (2000) quando se refere a "um dos maiores problemas da pesquisa em ciências da educação", qual seja, "[...] o de abordar o estudo do ensino de um ponto de vista normativo, o que significa dizer que os pesquisadores se interessam muito mais pelo que os professores deveriam ser, fazer e saber do que pelo que eles são, fazem e sabem realmente." (TARDIF, 2000, p.12, grifo nosso). Por outro lado, quando António Nóvoa pondera que o lugar da pesquisa da educação é

[...] na proximidade e na distância com as práticas profissionais e com as decisões políticas. Julgo que devemos abandonar os velhos modelos de disseminação da pesquisa, substituindo-os por uma reflexão e apropriação críticas. E devemos abandonar as culturas de salvação, substituindo-as pelo esforço intelectual de compreender e de agir criticamente (NÓVOA, 2011, p. 541, grifo nosso).

Quando os pesquisadores "se interessam muito mais pelo que os professores deveriam ser, fazer e saber" do que pelo que são, fazem ou sabem, cabe perguntar se não seria possível reconhecer proximidades entre essas propostas de pesquisa e políticas curriculares que se pretendem criticar. Se, ao contrário, admitimos que as práticas modelares são idealizações que geram muito mais angústia e sentimentos de culpa nos docentes - por se tratar de práticas projetadas por outros e, inalcançáveis, para tantos -, operamos com noções que reconhecem que a pluralidade e a singularidade das práticas educativas mostram sua complexidade e seu caráter irredutível a fórmulas ou a prescrições. Quando se empreende o "esforço intelectual de compreender e de agir criticamente", conforme sugere Nóvoa (2011), ou seja, quando a pesquisa reconhece que os docentes são "capazes" de gerir seu cotidiano escolar, que existem diferentes práticas e crenças sobre como ensinar a seus alunos, abre-se uma reflexão mais aprofundada que rejeita a subalternidade a que são submetidos os docentes por entre políticas curriculares e resultados de pesquisa. Talvez seja o momento de perguntar: Quando as políticas curriculares que incidem sobre as práticas docentes tornam-se objetos de investigação, quais são as questões que a elas endereçamos? 


\section{Agradecimentos}

Agradeço a Rodrigo Mendonça dos Santos, bolsista CNPq/AT, pela formatação e revisão das referências das páginas eletrônicas; aos integrantes do Grupo de Pesquisa "Currículo, Docência e Cultura" (CDC) do Programa de Pós-Graduação em Educação da UFF, em especial a Everardo Paiva de Andrade, pela riqueza das discussões sobre autonomia docente, que formam a base deste artigo. Agradeço ao CNPq e à Faperj pelo financiamento das pesquisas que dão origem a este texto.

\section{Referências}

ALMEIDA, M.J.P.M.Para superar as prescrições direcionadas ao professor de física. Tecné, Episteme y Didaxis , $n^{\circ}$. 26 Segundo semestre de 2009, p. 97-112.

APPLE, M. A política do Conhecimento Oficial: faz sentido a idéia de um currículo nacional? In: MOREIRA, A.F.B.; SILVA, T. T. Currículo, Cultura e Sociedade. São Paulo: Cortez Editora, 1994, p. 59-91.

AYRES et al. Políticas Curriculares e Autonomia Docente: o Currículo Mínimo em Debate. In: AZEVEDO; M.; VILELA, M.L. Cadernos de Resumo da III Jornada Currículo, Docência e Cultura: Sentidos de Autonomia Docente. Niterói: Universidade Federal Fluminense, 2015, p. 7 10.

CARLONE, H.; HAUNE-FRANK, J; KIMMET, S. (2010).Tempered radicals: elementar teachers' narratives of teaching Science within and against prevailling meanings of schooling. Cultural Studiesof Science Education, p. 5941-5965, 2010.

CATANI, D. B.; VICENTINI, P. P. "Minha vida daria um romance": lembranças e esquecimentos, trabalho e profissão nas autobiografias de professores. In: MIGNOT, Ana Crystina Venancio; CUNHA, Maria Teresa Santos (Orgs.). Práticas de memória docente. São Paulo - SP: Cortez, 2003. p. 149-166.

COCHRAN-SMITH, M. (1991). Teaching against the grain. Havard Educational Review, vol. 61, n. 3, August 1991.

COLINVAUX, D. Aprendizagem: as questões de sempre, a pesquisa e a docência. Ciência em Tela. V. 1, N. 1, 2008.

CONTRERAS, J. Autonomia docente. São Paulo: Cortez Editora, 2002.

CUNHA, L. A. O desenvolvimento meandroso da educação brasileira entre o estado e o mercado.

Educ. Soc., Campinas, vol. 28, n. 100 - Especial, p. 809-829, out. 2007

CURY, J. Alguns apontamentos em torno da expansão e qualidade do ensino médio no Brasil.

Ensino Médio como Educação Básica. In: MEC/SENEB/PNUD: Cadernos Seneb, n. 4. São Paulo:

Cortez, Brasília: Seneb, 1991.

FARIA FILHO, L. M. Aula, autoria e reconhecimento: implicações para a pesquisa sobre os currículos da escola básica. Palestra proferida na PUC-Rio, 2015.

GOODSON, I. A construção social do currículo. Lisboa: Educa, 1997.

HADDAD, S.; GRACIANO, M. Educação: direito universal ou mercado em expansão. São Paulo

Perspec., São Paulo, v. 18, n. 3, p. 67-77, Sept. 2004. 
LIMA, L. C.; Cidadania e Educação: Adaptação ao mercado competitivo ou participação na democratização da democracia? Educação, Sociedade \& Culturas, no 23, 71-90, 2005.

MARANDINO; M. SELLES, S. E.; FERREIRA, M.S. Ensino de Biologia: Histórias e Práticas em Diferentes Espaços Educativos. São Paulo: Cortez, 2009.

MACEDO, E. Base Nacional Curricular Comum: novas formas de sociabilidade produzindo sentidos para educação. Revista e-Curriculum, São Paulo, v. 12, n. 03, p.1530-1555, out/dez 2014.

MOREIRA, A.F.B. Em busca da autonomia docente nas práticas curriculares. Revista Teias v. 13, n. 27-47, jan./abr. 2012.

NÓVOA, A. et al. Pesquisa em educação como processo dinâmico, aberto e imaginativo: uma entrevista com António Nóvoa. Educação \&Realidade, v. 36, n. 2. Porto Alegre - RS, maio/agosto 2011. p. 533-543.

OLIVEIRA, D. A. A reestruturação do trabalho docente: precarização e flexibilização. Educação e Sociedade. Campinas, vol. 25, n. 89, p. 1127-1144, Set./Dez. 2004

OLIVEIRA, R. P. de. A transformação da educação em mercadoria no Brasil. Educ.

Soc. Campinas, v. 30, n. 108, p. 739-760, Oct. 2009.

POPKEWITZ, Thomas S. Números em grade de inteligibilidade. Dando sentido à verdade educacional. In: TURA, Maria de Lourdes Rangel; GARCIA, Maria Manuela Alves (org.).

Currículo, Políticas e Ação Docente. Rio de Janeiro: EdUERJ, p. 19-50, 2013.

SELLES, S.E.: Processos Históricos na Constituição da Disciplina Escolar Biologia: O Contexto de Produção dos BSCS. Relatório Técnico Final do projeto de Pós-doutorado. Financiado pelo CNPq, 2007.

SELLES, S. E.; ANDRADE, E. P. Políticas curriculares e subalternização do trabalho docente. Educação em Foco, v. 21, n.1, mar/jun 2016, p.39-64.

SELLES, S.E.; FERREIRA, M.S. O professor de Ciências e o movimento renovador dos anos de 1950/70: um estudo sócio-histórico. In: Cultura Escolar Migrações e Cidadania -Actas do VII Congresso LUSO-BRASILEIRO de História da Educação, p. 20-23, Junho 2008, Porto: Faculdade de Psicologia e Ciências da Educação (Universidade do Porto), p.6.

TARDIF, M. Saberes profissionais dos professores e conhecimentos universitários. Revista Brasileira de Educação, Jan/Fev/Mar/Abr, 2000. No 13, p. 5-24. . Saberes Docentes e Formação Profissional. Petrópolis - RJ: Vozes, 2002. 